\title{
Mucoepidermoid Carcinoma of the Breast Found during Treatment of Lymphoma
}

\author{
Minoru Fujino ${ }^{a}$ Daisuke Mori ${ }^{b}$ Michiaki Akashi ${ }^{b}$ Hidetaka Yamamoto $^{d}$ \\ Hitoshi Aibe $^{c}$ Kunishige Matake ${ }^{c} K^{2}$ engo Shirahane ${ }^{a}$ \\ ${ }^{a}$ Department of Breast Surgery, Saga Medical Center Koseikan, Saga, Japan; \\ ${ }^{b}$ Department of Pathology, Saga Medical Center Koseikan, Saga, Japan; \\ 'Department of Radiology, Saga Medical Center Koseikan, Saga, Japan; \\ ${ }^{\mathrm{d} D e p a r t m e n t}$ of Anatomic Pathology, Pathological Sciences, Graduate School of Medical \\ Sciences, Kyushu University, Fukuoka, Japan
}

\section{Keywords}

Mucoepidermoid carcinoma $\cdot$ Breast $\cdot$ Lymphoma

\begin{abstract}
A 71-year-old woman, previously treated for malignant lymphoma, was admitted to our hospital with a tumor in the right breast. The tumor size was $2.0 \mathrm{~cm}$ in diameter, and the borderline was unclear. The core needle biopsy material revealed an invasive adenocarcinoma with metaplastic change. Right mastectomy and sentinel lymph node biopsy was performed. Histologically, the tumor was composed of mucus-secreting, epidermoid, and intermediate cells. These findings confirmed the diagnosis as mucoepidermoid carcinoma (MEC) of the breast. MEC is more frequently observed in the salivary glands and occurs rarely in the breast, with an incidence of approximately $0.3 \%$ of all breast cancers. Because of the rarity of the disease, the clinicopathological features and clinical outcome have not been fully investigated. The relationship between MEC of the breast and lymphoma are unclear. Here we report a rare case of MEC of the breast.

(C) 2016 The Author(s) Published by S. Karger AG, Basel
\end{abstract}


 Oncology}

Fujino et al:: Mucoepidermoid Carcinoma of the Breast Found during Treatment of Lymphoma

\section{Introduction}

Mucoepidermoid carcinoma (MEC) is the most common histological type of both major and minor salivary gland neoplasms. Approximately half of these tumors occur in the major salivary glands and the other half occur in the minor salivary glands. The ratio of men to women diagnosed with MEC is three to two [1]. MEC also arises in the pancreas [2], lacrimal gland [3], skin adnexa [4], bile duct [5], intestinal mucosa [6], and breast [7]. MEC in the breast represents an unusual variant of breast cancer that accounts for about $0.3 \%$ of breast carcinomas. Predicting prognosis of MEC is difficult as it shows a wide range of low to high grade.

A previous study in 1996 showed that MEC of the salivary glands exhibits $t(11 ; 19)$ (q21;p13) translocation [8]. Cytological features of MEC breast tumors are similar to MEC of the salivary glands and include mucus-secreting, epidermoid, and intermediate cells. Because of the rarity of the disease, only a limited number of case series have been published, and thus, the clinicopathological features and clinical outcome of MEC of the breast have not been fully investigated. Here we report a case of MEC of the breast diagnosed by pathological assessment of the lesion.

\section{Case Presentation}

A 71-year-old Japanese postmenopausal woman was referred to us for evaluation of a tumor in the right breast. She had suffered from malignant lymphoma (diffuse, medium to large B-cell lymphoma) treated with chemotherapy consisting of eight cycles of R-CHOP and radiotherapy (total $46 \mathrm{~Gy}$ ) to the head for the previous 3 years. She had undergone hysterectomy for myoma of the uterus at the age of 41 years. In addition, she had a medical history of hypertension and hyperlipidemia. There was no remarkable family history.

Physical examination demonstrated an elastic hard lump on palpation located in the lower lateral quadrant of the right breast. The tumor size was $2.0 \mathrm{~cm}$ in diameter, and the borderline was unclear. No skin change or dimpling was seen. Nipple charge was not evident. No axillary lymph node swelling was found. All laboratory data were unremarkable, and there was no increase of tumor markers such as CEA and CA15-3.

Mammography of the right breast showed an unclear mass with accumulation of calcification (Fig. 1). Ultrasonography showed a hyperechoic lesion within a hypoechoic area, with rough surface (Fig. 2). Enhanced magnetic resonance imaging revealed a mass of high intensity in the right breast (Fig. 3).

Histopathological evaluation of the core needle biopsy material revealed an invasive adenocarcinoma with metaplastic change, but definitive histological diagnosis could not be determined. There was no proliferation of atypical lymphocytes.

The patient underwent right mastectomy and sentinel lymph node biopsy. The frozen section of the sentinel lymph node was found to be free of disease by intraoperative diagnosis.

Macroscopically, cut sections revealed a white, solid, and well-circumscribed tumor measuring approximately $17 \times 15 \mathrm{~mm}$ (Fig. 4). Histopathologically, the tumor was composed of cancer cells forming papillary or tubular structures with an abundant mucus cytoplasm, which was positive for periodic acid-Schiff staining, and accompanied by psammoma bodies (Fig. 5, Fig. 6). Squamoid cancer cells proliferated in sheet-like patterns, but intracellular 
Fujino et al:: Mucoepidermoid Carcinoma of the Breast Found during Treatment of Lymphoma

bridges or keratinization were not seen (Fig. 7). Intermediate cells were also seen (Fig. 8). In the stroma, many inflammatory cells proliferated around the tumor.

Immunohistochemical findings showed that the tumor cells were positive for cytokeratin 7, cytokeratin 5/6, cytokeratin 14, epidermal growth factor receptor, p63, and MUC-1, and negative for gross cystic disease fluid protein-15, estrogen receptor, progesterone receptor, and human epidermal growth factor receptor-2. Ki-67 labeling index was $22 \%$. The mitotic index was one mitosis per 10 high-magnification fields. No vascular or perineural invasions were observed. Histological examination determined MEC of the breast, intermediate histological grade.

\section{Discussion}

MEC was first reported by Foote et al. [7] as a malignant epithelial neoplasm arising in major and minor salivary glands. Salivary gland MEC is the most frequent type of salivary gland tumors and represents approximately $30 \%$ of malignant tumors of salivary glands. It is characterized by a mixture of mucous-secreting, epidermoid, and intermediate cells.

Foote et al. [7] proposed two distinct forms of MEC, the low-grade form and high-grade form. Recently, Goode et al. [9] proposed a grading system in which five histopathologic features are used to define low-, intermediate-, and high-grade tumors. The 5-year survival rates in low-, intermediate-, and high-grade tumors were 97, 90, and 54\%, respectively. In high-grade tumors, high Ki-67 labeling index ( $>10 \%)$ correlated with decreased patient survival, increased recurrence, and metastasis.

MEC is characterized by a recurrent chromosomal translocation $t(11 ; 19)(q 21 ; p 13)$ [8]. This alteration results in a MECT1-MAML2 fusion. The fusion transcript fuses the binding of exon 1 of mucoepidermoid carcinoma translocated 1 (MECT1), a novel gene of unknown function, at 19p13 with exons 2-5 of a novel member of the Mastermind-like gene family (MAML2) at 11q21 [10]. This fusion transcript may be specific to MEC and associated with a distinct MEC subset that exhibits favorable clinicopathologic features and an indolent clinical course [11]. Preliminary studies of other carcinoma subtypes of the breast and thyroid are negative for this fusion gene [12]. Recently, Nakano et al. [13] reported that HER2 gene amplification and an increased EGFR gene copy number were detected in high-grade MEC irrespective of MAML2 fusion status. They suggested that HER2 or EGFR gene abnormality could play an important role in the development of the progression from MAML2 fusion-positive low-/intermediate-grade to high-grade in a subset of MEC [13]. In our case, MAML2 fusion was not detected using reverse transcriptase-polymerase chain reaction.

In 1979, Patchefsky et al. [14] for the first time reported two cases of MEC of the breast. MEC of the breast is an unusual variant of breast cancer and similar to its salivary counterpart. The histological features include varying proportions of mucus-secreting, epidermoid, and intermediate cells, as recognized by the World Health Organization [15]. MEC of the breast is rare, with an incidence of approximately $0.3 \%$ of all breast cancers. Because of the rarity of the disease, only a limited number of case series have been published and thus the clinicopathological features and clinical outcome of MEC of the breast have not been fully investigated.

Horie et al. [16] described the prognosis of 23 breast MEC cases in which 4 patients died of breast cancer, 2 died of other causes, 1 patient remained alive with recurrence, and 14 patients remained alive without recurrence. Patients with low-grade MEC were disease free in the follow-up period, whereas high-grade MECs usually showed aggressive behavior with 


\section{Case Reports in Oncology}

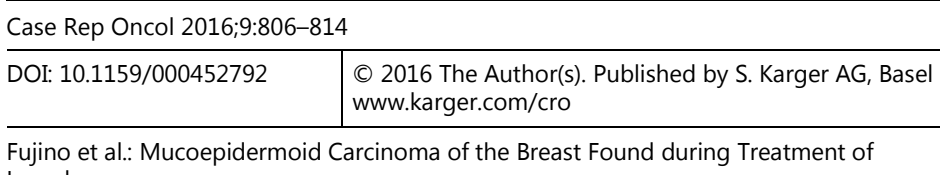

Lymphoma

metastasis to axillary nodes and distant organs [17]. Immunohistochemically, MUC5AC is expressed in more than $50 \%$ of high-grade tumors and MUC1 expression correlates with shorter disease-free survival [18].

According to the past reports, no case of MEC of the breast with psammoma bodies has yet been described until the current study. Psammoma bodies are typically seen in papillary adenocarcinoma of thyroid and meningioma. In MEC, the presence of psammoma bodies are frequently observed in thyroid MEC rather than salivary or pulmonary MEC [19]. Maruta et al. [20] reported that psammoma bodies may be an indicator of lymph node metastasis in papillary adenocarcinoma of thyroid. The significance is unclear, but we cannot deny the possibility of a role of psammoma bodies in MEC.

Breast lymphoma is a rare tumor. None of the imaging features of breast lymphoma are pathognomonic [21]. Because the imaging features showed atypical findings as invasive breast carcinoma in this case, and our case had a medical history of malignant lymphoma, we considered breast lymphoma as the differential diagnosis. However, histopathologically there was no proliferation of atypical lymphocytes, and thus we did not diagnose breast lymphoma.

A previous study reported a case of MEC of the parotid grand in a child with acute lymphoblastic leukemia (ALL) treated with chemotherapy and irradiation [22]. In children previously treated for ALL, second cancers of the salivary glands are most often related to previous head and neck irradiation. MEC is the most common cancer of the major salivary glands occurring after irradiation [23]. On the other hand, Gibod et al. [22] reported that MEC occurred in a patient of ALL in childhood treated without irradiation, only by chemotherapy. In the current case, she was treated with multidrug chemotherapy and irradiation to the head. The relationship between MEC of the breast and lymphoma has not been described, but the possibility of a correlation between the two remains.

In conclusion, we report herein a case of MEC of the breast. Because MEC of the breast is a rare entity, there is no standard treatment and the prognostic features are not well established. Careful follow-up of this patient is required.

\section{Acknowledgements}

The authors thank Dr. Shuu Ichihara (National Hospital Organization Nagoya Medical Center) for his assistance and cooperation.

\section{Statement of Ethics}

The authors have no ethical conflicts to disclose.

\section{Disclosure Statement}

We do not have any financial relationship with any organization that sponsored our research. 
Fujino et al.: Mucoepidermoid Carcinoma of the Breast Found during Treatment of Lymphoma

\section{References}

1 Barnes L, Eveson J, Reichart P, Sidransky D, editors: Pathology and Genetics of Tumours of the Head and Neck. WHO Classification of Tumours. Lyon: IARC Press; 2005.

-2 Onoda N, Kang SM, Sugano S, Yamashita Y, Chung YS, Sowa M: Mucoepidermoid carcinoma of the pancreas: report of a case. Surg Today 1995;25:843-847.

-3 Dithmar S, Wojno TH, Washington C, Grossniklaus HE: Mucoepidermoid carcinoma of an accessory lacrimal gland with orbital invasion. Ophthal Plast Reconstr Surg 2000;16:162-166.

-4 Riedlinger WF, Hurley MY, Dehner LP, Lind AC: Mucoepidermoid carcinoma of the skin: a distinct entity from adenosquamous carcinoma: a case study with a review of the literature. Am J Surg Pathol 2005;29:131-135.

-5 Choi D, Kim H, Lee KS, Lee KG, Park CK: Mucoepidermoid carcinoma of the liver diagnosed as abscess: report of a case. Surg Today 2004;32:1004-1007.

6 Sato H, Kuroda M, Maruta M, Maeda K, Koide Y: Mucoepidermoid carcinoma of the ascending colon: report of a case. Surg Today 2001;32:1004-1007.

7 Foote FW, Becker WF, Stewart FW: Muco-epidermoid tumors of salivary glands. Ann Surg 1945;122:820-840.

-8 El-Naggar AK, Lovell M, Killary AM, Clayman GL, Batsakis JG: A mucoepidermoid carcinoma of minor salivary gland with $\mathrm{t}(11 ; 19)(\mathrm{q} 21 ; \mathrm{p} 13.1)$ as the only karyotypic abnormality. Cancer Genet Cytogenet 1996;87:29-33.

-9 Goode R, Auclair P, Ellis G: Mucoepidermoid carcinoma of the major salivary glands. Clinical and histopathologic analysis of 234 cases with evaluation of grading criteria. Cancer 1998;82:1217-1224

10 Tonon G, Modi S, Wu L, Kubo A, Coxon AB, Komiya T, O’Neil K, Stover K, El-Naggar A, Griffin JD, Kirsch IR, Kaye FJ: t(11;19)(q21;p13) translocation in mucoepidermoid carcinoma creates a novel fusion product that disrupts a Notch signaling pathway. Nat Genet 2003;33:208-213.

-11 Okabe M, Miyabe S, Nagatsuka H, Terada A, Hanai N, Yokoi M, Shimozato K, Eimoto T, Nakamura S, Nagai N, Hasegawa Y, Inagaki H: MECT1-MAML2 fusion transcript defines a favorable subset of mucoepidermoid carinoma. Clin Caner Res 2006;12:3902-3907.

-12 Behboudi A, Enlund F, Winnes M, Andrén Y, Nordkvist A, Leivo I, Flaberg E, Szekely L, Mäkitie A, Grenman R, Mark J, Stenman G: Molecular classification of mucoepidermoid carcinomas - prognostic significance of the MECT1-MAML2 fusion oncogene. Genes Chromosomes Cancer 2006;45:470-481.

13 Nakano T, Yamamoto H, Hashimoto K, Tamiya S, Shiratsuchi H, Nakashima T, Nshiyama K, Higaki Y, Komune S, Oda Y: HER2 and EGFR gene copy number alterations are predominant in high-grade salivary mucoepidermoid carcinoma irrespective of MAML2 fusion status. Histopathology 2013;63:378-392.

14 Patchefsky AS, Frauenhoffer CM, Krall RA, Cooper HS: Low-grade mucoepidermoid carcinoma of the breast. Arch Pathol Lab Med 1979;103:196-198.

15 Tavassoli FA: Adenosquamous carcinoma. In: Tavassoli FA, Devilee P, editors. World Health Organization Classification of Tumours. Pathology and Genetics of Tumours of the Breast and Female Genital Organs. Lyon: IARC Press; 2003. p. 39-40.

16 Horii R, Akiyama F, Ikenaga M, Iwase T, Sakamoto G: Muco-eidermoid carcinoma of the breast. Pathol Int 2006;56:549-553.

17 Foschini MP, Reis-Filho JS, Eusebi V, Lakhani SR: Salivary gland-like tumors of the breast: surgical and molecular pathology. J Clin Pathol 2003;56:497-506.

18 Palermo M, Pinto MB, Zabetti JS, Silva AR: Primary mucoepidermoid carcinoma of the breast: a case report with immunohistochemical analysis and comparison with salivary gland mucoepidermoid carcinomas. Pol J Pathol 2013;64:210-215.

19 Minagawa A, Iitaka M, Suzuki M, Yasuda S, Kameyama K, Shimada S, Kitahama S, Wada S, Katayama S: A case or primary mucoepidermoid carcinoma of the thyroid: molecular evidence of its origin. Clinico Endocrinology 2002;57:551-556.

20 Maruta J, Noguchi S, Yamashita H: Psammoma bodies in thyroid disease. J Jpn Soc Clin Cytol 1997;36:563-567.

21 Lee KC, Lee SH, Sung KH, Ahn SH, Choi J, Lee SH, Lee JH, Hong J, Park SH: A case of primary breast diffuse large B-cell lymphoma treated with chemotherapy followed by elective field radiation therapy: a brief treatment pattern review from a radiation oncologist's point of view. Case Rep Oncol Med 2015;2015:907978.

-22 Gibod LB, Boman F, Josset P, Parker JL: Mucoepidermoid carcinoma of the parotid gland in a child previously treated for acute lymphoblastic leukemia. Pediatr Blood Cancer 2005;44:673-675.

23 Spitz MR, Batsakis JG: Major salivary gland carcinoma: descriptive epidemiology and survival of 498 patients. Arch Otolaryngol 1984;325:1330-1336. 


\section{Case Reports in Oncology}

\begin{tabular}{l|l}
\hline DOI: $10.1159 / 000452792$ & ( 2016 The Author(s). Published by S. Karger AG, Basel \\
\hline
\end{tabular} www.karger.com/cro

Fujino et al.: Mucoepidermoid Carcinoma of the Breast Found during Treatment of Lymphoma

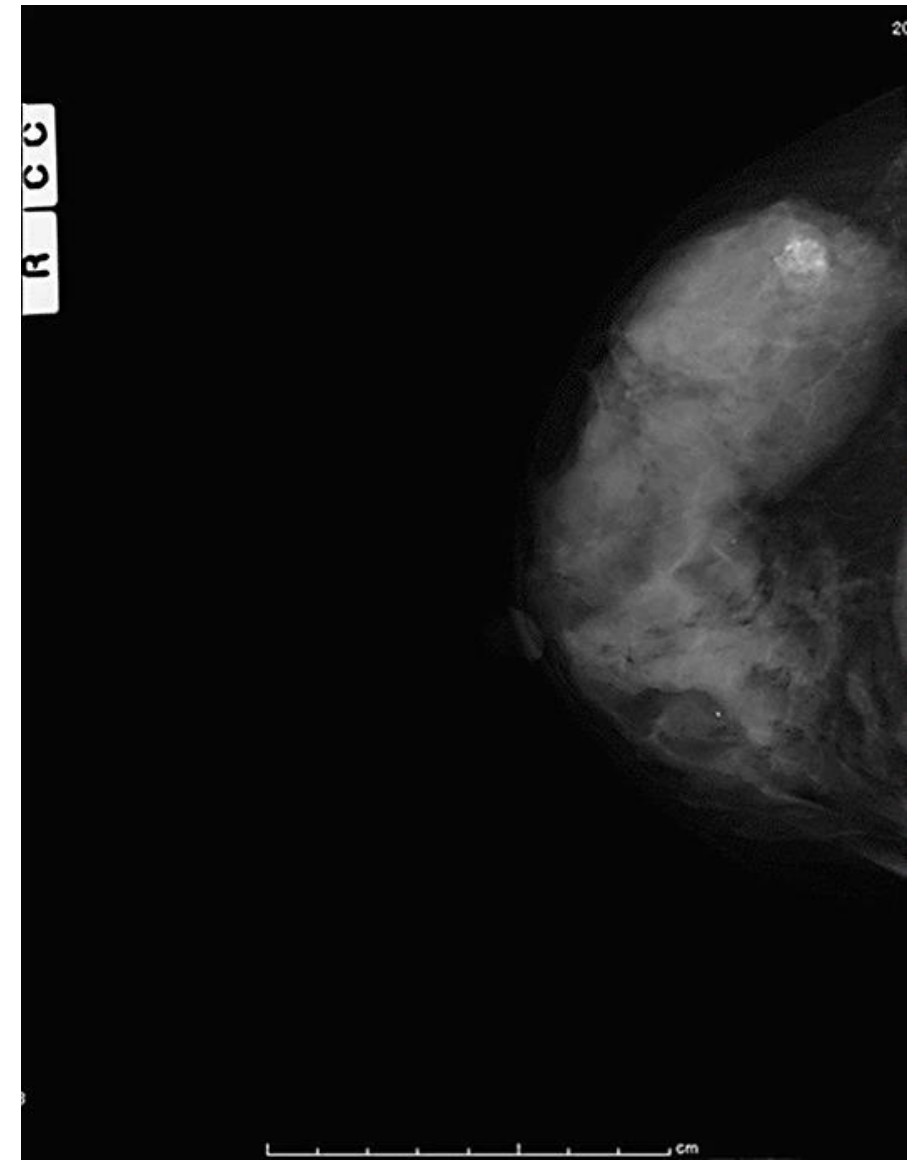

Fig. 1. Mammography showed unclear mass with accumulation of calcification. 


\section{Case Reports in Oncology}

Fujino et al.: Mucoepidermoid Carcinoma of the Breast Found during Treatment of Lymphoma

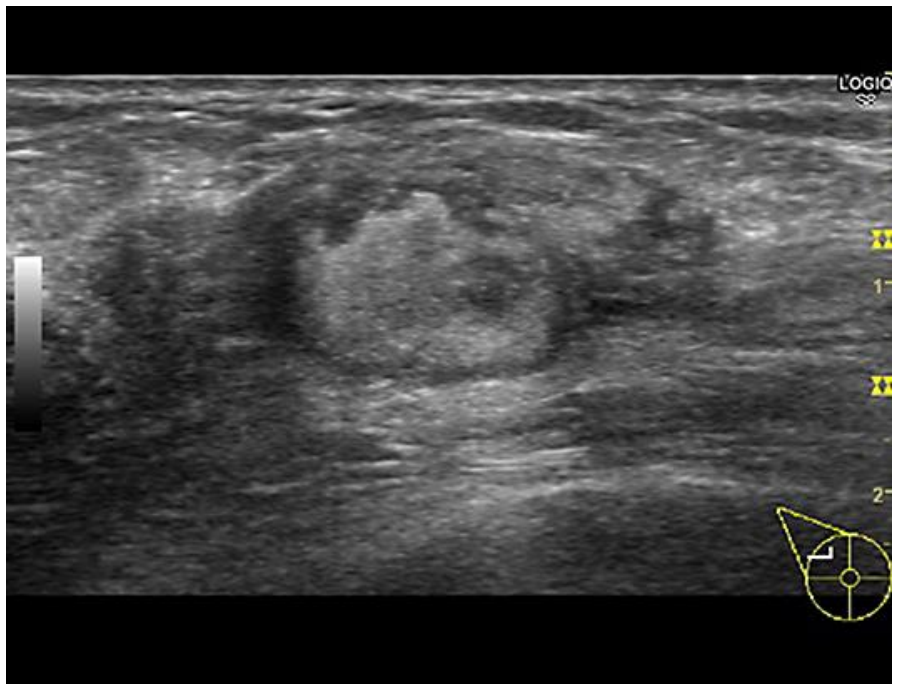

Fig. 2. Ultrasonography showed a hyperechoic lesion within a hypoechoic area, with rough surface.

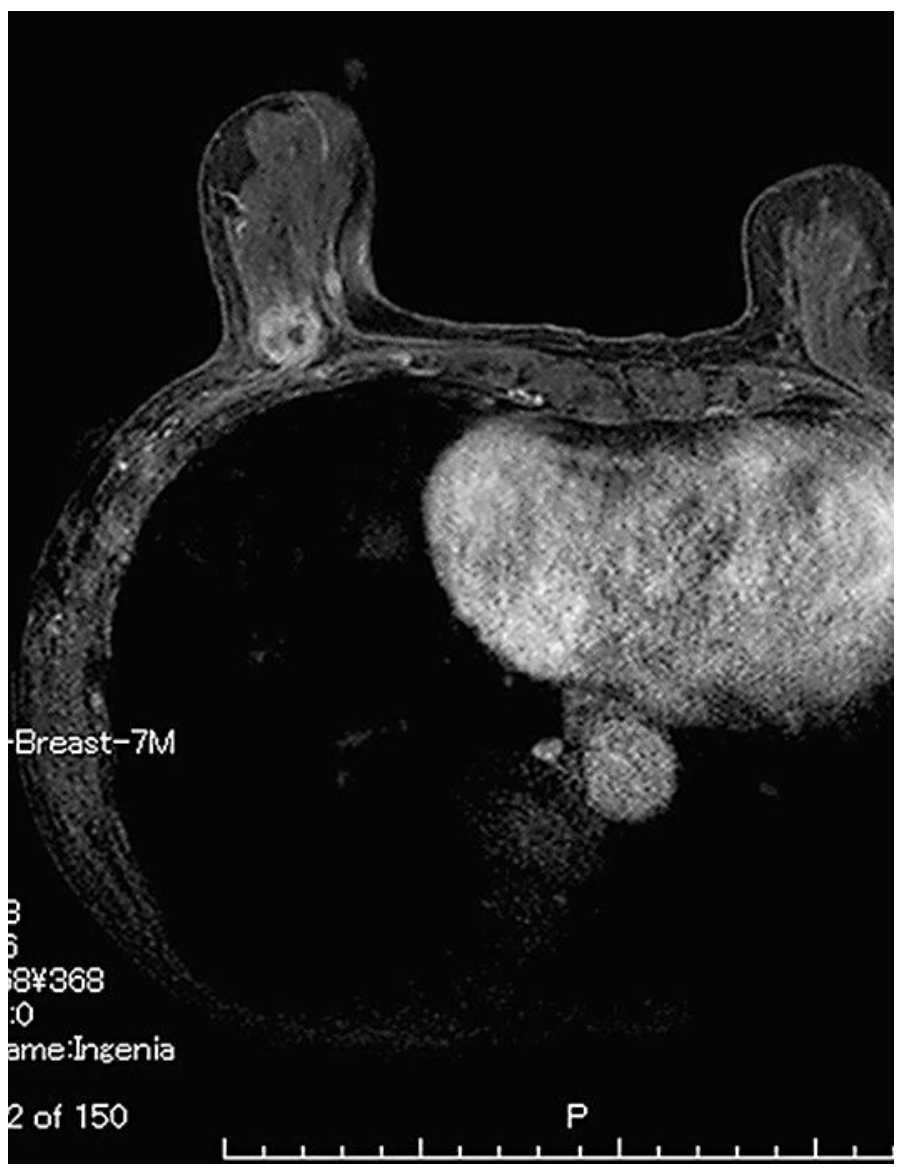

Fig. 3. Enhanced magnetic resonance imaging revealed a mass of high intensity in the right breast. 


\section{Case Reports in Oncology}

\begin{tabular}{l|l}
\hline Case Rep Oncol 2016;9:806-814 \\
\hline DOI: 10.1159/000452792 & $\begin{array}{l}\text { ○ 2016 The Author(s). Published by S. Karger AG, Basel } \\
\text { www.karger.com/cro }\end{array}$ \\
\hline
\end{tabular}

Fujino et al.: Mucoepidermoid Carcinoma of the Breast Found during Treatment of Lymphoma

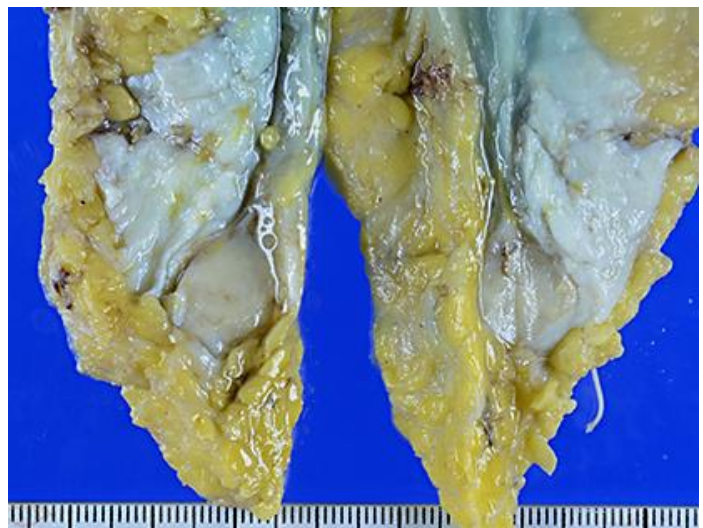

Fig. 4. Macroscopically, cut sections demonstrated white, solid, and well-circumscribed tumor.

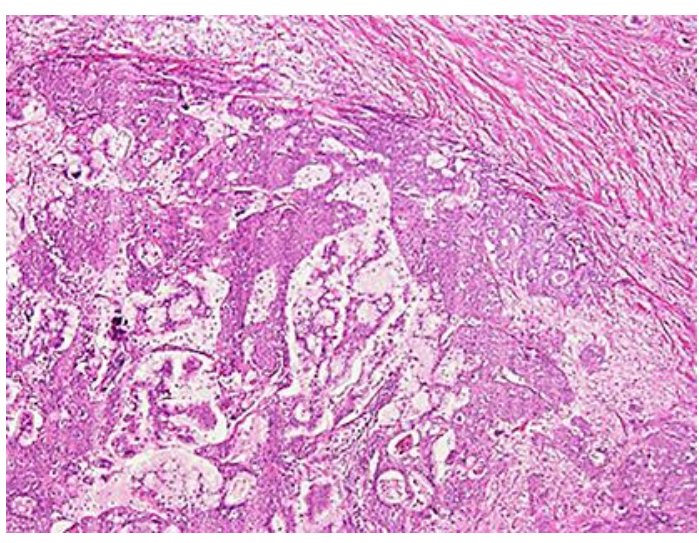

Fig. 5. Microscopically, the tumor showed predominantly solid pattern with focal mucin and psammoma body $(\times 20)$.

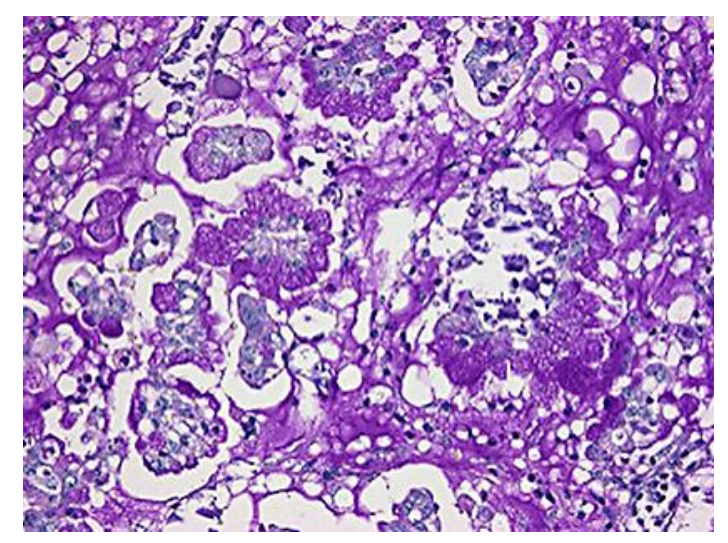

Fig. 6. The mucus-containing cancer cells formed papillary or tubular structures, which were positive for periodic acid-Schiff staining $(\times 200)$. 


\section{Case Reports in Oncology}

Case Rep Oncol 2016;9:806-814

DOI: $10.1159 / 000452792$

C 2016 The Author(s). Published by S. Karger AG, Basel

Fujino et al.: Mucoepidermoid Carcinoma of the Breast Found during Treatment of Lymphoma

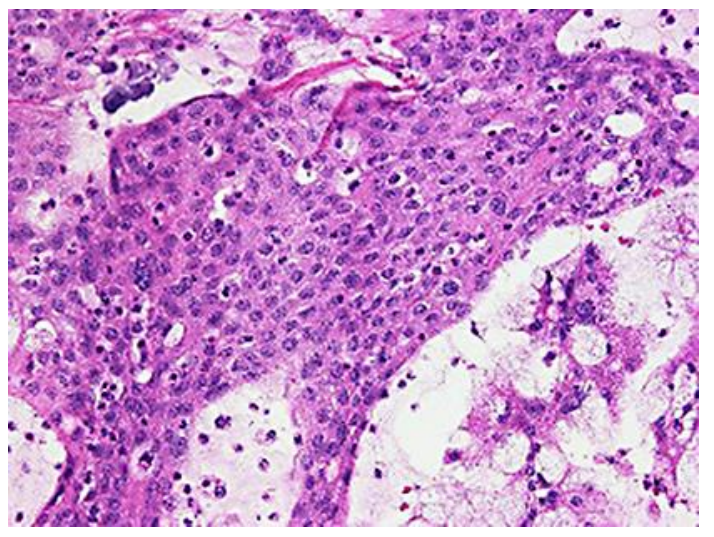

Fig. 7. Squamoid cancer cells proliferate in sheet-like patterns $(\times 200)$.

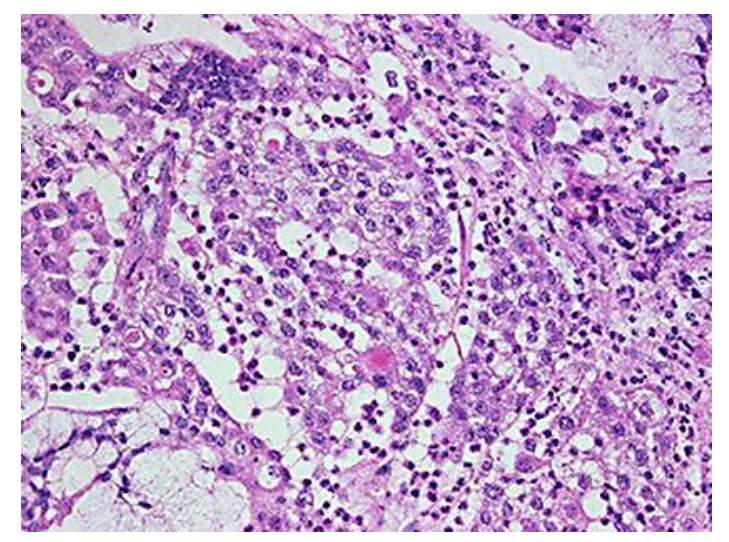

Fig. 8. Intermediate cells $(\times 200)$. 